\title{
Is Data the New Coal? - Four Issues with Christian Fuchs on Social Media
}

\author{
CHRISTOPH RAETZSCH, Freie Universität Berlin, Germany
}

\author{
The word is community \\ We shout it with impunity \\ It's so uncool \\ It's incendiary \\ No slogans, no sound bites, but a long term plan \\ Teaching is the framework \\ Building chains of command \\ So when the lizard man sticks out his tongue \\ We pull out our scissors and do a hit and run \\ This is the digital underclass \\ Asian Dub Foundation "Hypocrite" (1998)
}

\section{Introduction}

The plurality, ambiguity and heterogeneity of ways in which social media are significant today bespeaks, maybe even fundamentally, the possibility of a generalizable theoretical perspective. Recognising this challenge means to question the very possibility of a single analytic principle: Not an easy sacrifice for the disciples of the Enlightenment - and its dialectics. If we conceive of perspective not only as an artistic convention but as a model of control and knowledge, in which observer and object are put into relation, we may realise that the phenomenon of social media puts an end to the difference between observer and object. This principle of perspective was eloquently summarised by the art historian Erwin Panofsky in 1927, who wrote that "the history of perspective may be understood with equal justice as a triumph of the distancing and objectifying sense of the real, and as a triumph of the distance-denying human struggle for control" (Panofsky [1927] 1997: 67). Perspective was 'invented' to assure that a representation of a perceived reality would respect the proportional dimensions of objects in space, while firmly situating a one-eyed observer at the centre of this representational space, as an overseer and controlling agent. The consequence of adopting perspective for any observer is being locked into a position, a position in which certain objects necessarily diminish in importance or can no longer be seen at all.

When reading through Christian Fuchs's most recent works on social media, culture and the internet economy - most notably his short Social Media - A Critical Introduction (2014) - the argument unfolds as a diorama of snapshots made from a single perspectival position. It is as if the social realities of social media are deliberately ignored, sidelined and marginalised, only to arrive at the rather unsurprising notion that social media platforms create an 'audience commodity' to obtain 
data that can be traded with advertisers. Data is the new coal: Data drives the servers, apps, profits and desires just as coal was driving the first industrial revolution. At least, that is how Fuchs presents his theory of social media through the Ur-Marxist, 19th century lens that he has adopted. And in this perspective, any meaningful interaction users may have over social media appear as little more than soot particles clogging the channels of human communication.

But let's start with the observer, himself.

Since his appointment at the University of Westminster in 2012, Christian Fuchs has shown a remarkable zest in arguing for a radical rethinking of critical approaches to social media, the economy of global communications and the role of media in global hegemonies of power. As Director of the Communication and Media Research Institute ( $\underline{\text { CAMRI }}$, as editor of the open-access journal triple $C$, and as an author of numerous books and articles, Fuchs has repeatedly made the case that "Marx can help us a lot" in understanding the entanglements and contradictions of power, capital and technology in the present, and to envision "a better future"

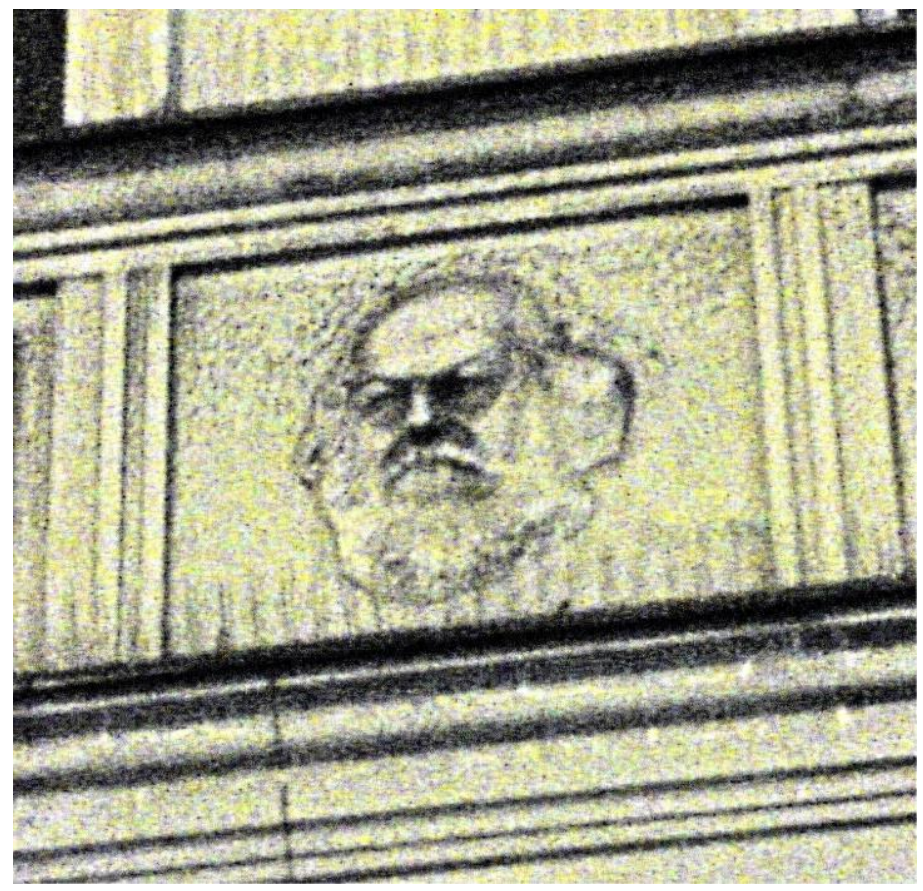
for the uses of social media (2014a: 12). Within the last two years alone, Fuchs has published four major books that each in their own way develop his approach to social media's cultural political economy in a globalised society. The basic strands of his analytic approach, however, can be found in condensed form in Social Media - A Critical Introduction, which is designed as a course book initiating students to critical debates and perspectives in social media scholarship. Written in an approachable style, the book underlines its didactic ambitions with an extensive body of questions and suggestions for classroom discussion and further research (see also the review by Jenny Davis, 2014). Because of its short format and comparatively unique market position, it is very likely that Social Media will be a welcome resource in undergraduate education. As readers are confronted with a broad range of subjects in a succinct fashion, the volume may prove to be instrumental in questioning widely held beliefs about the uses and structures of social media in contemporary societies. Whether readers will actually follow his theoretical premises is a challenge Fuchs seems willing to accept.

In the first part of this essay I will briefly review Social Media itself, introducing the main arguments and pointing out the benefits and shortcomings of the book. In the main part, I want to concentrate on four major issues that Fuchs addresses in Social Media and in other publications. These issues are likely to inform debates about social media in a broad range of disciplines and they 
are pertinent to any critique or theory of social media in contemporary societies.

First, is Social Media an introduction, a theory, or a critique of social media? The book outlines basic elements of Fuchs' Marxist framework. But the abridged, didactic format of an introduction leads to a very troubling and peculiar form of 'theoretical sampling', which fails to elucidate the relevance of Karl Marx's work in relation to social media. One consequence is that the role and status of data in the analysis remains unclear and one-dimensional.

Second, what kind of social media does Fuchs have in mind? There is an ambiguous tension in his argument that social media are primarily defined as "applications" by large global players, such as Google, Facebook, Twitter or Weibo, while he acknowledges that Wikipedia, Wikileaks or similar open-source platforms are embodying positive and beneficial social principles of collaboration and cooperation. The unresolved opposition of social media ${ }^{\circledR}$ as trademarked applications and social media as technologies of collaboration remains a blind spot in Fuchs' argument.

Third, what is the status of free labour and exploitation in Fuchs's view of social media? A cornerstone of his theorising of social media is that social media usage is exploitative just as mining for rare sands in Sub-Saharan Africa or working in Foxconn's electronics sweatshops is. But his argument on the creation of the 'audience commodity' through data is far from convincing and needs to be discussed in context.

Fourth, and last, what kind of concept does Fuchs have of users? He typically emphasises the structurally exploitative nature of social media platforms because the sheer volume of user activity is an infinite source of surplus value on the side of owners and shareholders. By associating power primarily with questions of ownership, Fuchs deliberately avoids considering the dimensions of user agency, not to say of individual creativity or rational judgement in theorising social media.

\section{I) The Hidden Structures in Social Media}

Starting with Internet and Society (Routledge 2008) and Foundations of Critical Media and Information Studies (Routledge 2012), and continuing with Digital Labour and Karl Marx (Routledge 2014) and OccupyMedia! (Zero Books 2014), Christian Fuchs has argued for a radical rethinking of the role of Information and Communication Technology (ICT) in both the globalised economy and in contemporary politics and culture (see also the edited volumes Trottier \& Fuchs 2014; Fuchs \& Sandoval 2014). Digital Labour and Karl Marx can be read as emblematic of Fuchs' approach to social media, which is informed by his conceptual framework of the international division of digital labour (IDDL). The key argument here is that both the industrial production of communication devices and the production of services (software, platforms, applications) "[contain] multiple forms of labour that are invisible to the user" (2013: 3). The polished surfaces of gadgets, just like the playful interfaces of websites and services, obscure the underlying processes of production, domination and exploitation that drive value and profit generation in the IT industries 
worldwide. For Fuchs, the global value chain of ICTs begins with exploitation in African mines for rare sands, continues in Chinese IT factories and Indian software and customer service industries, and ends with users generating content on a voluntary and gratuitous basis in exchange for symbolic forms of recognition. This hidden economy of global flows of materials, goods and information embodies the true nature of current (social media or cyber-) capitalism. The main thrust of his critique is to juxtapose the (supposedly) pleasurable experiences of users with the overall exploitative framework of production and distribution within the global social media and electronics industries. The post-industrial age of media, knowledge and information is, at least in Fuchs' interpretation, not so post-industrial after all but enhances and aggravates structural inequalities of capitalism on a global scale that have existed from its very beginnings.

Social Media - A Critical Introduction should be regarded at the intersection of Digital Labour and Karl Marx and OccupyMedia!, which also appeared in 2014. Fuchs connects his analyses of digital labour with the social impact of new media in the domains of political action, knowledge production and the new constitution of the public sphere. Fuchs's critical introduction to the political economy of social media contrasts the supposed openness of the Internet with the growing global socio-economic hegemony of certain platforms like Facebook or Google, a dilemma that many critics and scholars would certainly agree with. Fuchs's approach, however, is classically Marxist in the sense that it addresses 'inherent contradictions' in contemporary Capitalism, employs 'dialectical reason' to expose structures of domination, and is avowedly normative in its political demands: "The book is based on the normative assumption that we need a society and social media that benefit not just some of us, but all of us" (2014a: 11). By looking at the inherent contradictions in current developments of both capitalism and the culture and economy of social media, Fuchs wants to go beyond corporate definitions of the web, in a way resuscitating the spirit of free and open cooperation that informed the early stages of Internet communication and development: "The book analyses the actuality of social media in contemporary capitalism and the potentials and limits for overcoming the corporate character of social media and for establishing a truly participatory Internet within the context of a participatory democracy" (ibid. 24). Fuchs thus wants to affirm a political imperative of a free, open web in democratic society at a historical moment when this freedom risks being co-opted by profit interests and submerged in monopoly structures of access to and control of knowledge and information.

The book is structured around three sections of very different length. In Section One, Fuchs discusses the 'Foundations' of his critical approach, especially the relation of social media to participatory culture and to communication power. Section Two ('Applications') concentrates on different companies (Google, Facebook, Twitter) and their platforms in relation to concepts like transparency, privacy, or the public sphere. Fuchs also discusses Wikipedia and Wikileaks here, as vanguards of "socialist", egalitarian media. The last Section Three is very brief, arguing for the political need to establish 'truly social media' in opposition to their exploitative and corporatized current forms.

The foundations that Fuchs claims for his critical framework are found in classics of sociological 
theory (Emile Durkheim, Max Weber, Ferdinand Tönnies) and Marxist critical theory, of course. Fuchs is interested in understanding the involvement of media at different levels of sociality. He points to the decisive difference between social networks and technical networks because these two concepts of networks seem to converge in social media applications. Whereas the technical infrastructure of a network is installed on a proprietary basis to drive capitalist value creation, networks between social actors foster cooperation and participation. According to Fuchs, the first stage of social media in the early web was defined by cognition, meaning that media created new ways of perceiving the world. The second stage of proprietary social media platforms is built around communication. In the third stage, the author foresees a strong shift toward cooperative production among users (2014a: 42-49), forms of production that go beyond what Henry Jenkins called "participatory culture." Fuchs singles out Jenkins as a straw man to stand for a fundamental misconception of participation, where demands for political power are eschewed in favour of 'softer' notions of peer-production, user-generated content or 'produsage' (Bruns 2008). According to Fuchs, participation must go beyond collective meaning-making and gratuitous product evaluation: participation must be part of an affirmative political project.

Fuchs here criticises the (alleged) bias of media and communication scholars to interpret any form of communication as an act of public participation. He demands that "Media and Communication Studies should forget about the vulgar and reductionist notion of participation (simply meaning that users create, curate, circulate or critique content) and focus on rediscovering the political notion of participation by engaging with participatory democracy theory" (2014a: 65). Symptomatic of this misconception of participation and communication, according to Fuchs, is Manuel Castells's term 'mass self-communication', because the promise of individual autonomy in social media is contradicted by their structural hegemony, concentration of ownership and commercialism. Participation needs to be tied to questions of power and inequality. In distinction from John B. Thompson's focus on 'symbolic power' in the media (1995), Fuchs underlines that dimensions of political, economic and cultural power together shape the current media system. Two charts on pages 78-81 show how the dominance of certain cultural ideas is also linked to political and economic power and how resources would need to be redistributed to allow for forms of media 'counter-power' to emerge on a grand scale. The entire chapter four on Social Media and Communication Power offers a detailed and valuable critique of Castells's term 'mass selfcommunication' and forms of power as they operate both inside and in opposition to media industries.

Against this theoretical background, it should be fair to say that the book as a whole puts forward two core theses. The first concerns the role of labour, exploitation and ownership in relation to social media. In Fuchs's view, social media continue the basic structural (power) asymmetry between capitalist entrepreneurs (owners) and salaried employees (workers) that was established in early 19th century capitalism. The only difference today is that the creation of content through users (UGC) is not remunerated at all and is available as an infinite resource for value creation. Data from user-activity is extracted, analysed and sold to advertisers. Building on Dallas Smythe's term of the 'audience commodity' (Smythe 1982; Fuchs 2012b) Fuchs argues that social media are 
structurally geared toward finding and creating audiences for advertising clients. The individual social media user is only interesting as a bit in an aggregate of data that can be analysed for the needs of advertising clients looking to interest customers for companies, products and services. The trade-off between free usage and the profit demands of shareholders, Fuchs seems to be saying, is clearly in favour of the owners of social media sites and their corporate partners. Just as user creativity and communication is exploited, so are employees of dotcom companies and media workers in general. Often being expected to engage in innovative projects and auxiliary team activities in their leisure time (playlabour), employees in the IT industries create capital surplus value for their employers through the exploitative mechanisms of symbolic incentives and immaterial rewards. The second, political core thesis of Social Media is that proprietary applications of individual companies embody and promote an ideology of participation and sociality that contradicts or is even opposed to the ideals of participatory democracy. This argument is made especially in connection to Facebook, where Fuchs discusses the issue of surveillance and privacy, and in relation to Twitter, which he (among many others) likens to a corporate space where new public spheres are emerging. Other examples include Wikipedia as a commons space of equal access and production, and Wikileaks as a new means of creating transparency in society. Fuchs singles out these latter two platforms as models of what he terms 'info-communism' (243) - "a classless society in which all humans have wealth in terms of resources, time, skills, networks, relations, capacities, etc. - a society of well-rounded individuals" (247).

Social Media is clearly written for newcomers in critical and social theory, who to a certain degree depend on Fuchs for putting questions and theories in perspective. But the cursory and aleatory fashion in which he 'samples' arguments and stocks of knowledge from critical theory and critiques of the media is disorienting, often merely hinting at theories rather than explaining arguments, enumerating examples rather than contextualising cases. Again and again we are offered endless lists of provocative questions (pp. 8-10), citations (p. 33) or analytic categories in critical theory (p. 15; 21f.), that are not explained or differentiated in their relevance. The problem with such lists is that they are presented as forms of evidence (of domination, of the necessity for critical theory, or of exploitation), while the criteria for their selection and possible counter-examples are not made available to readers. On the editorial side, the book appears as a quickly composed collection of separate documents. Some subchapters consist of only a few lines, e.g. a meagre 12 lines dedicated to Ferdinand Tönnies's concept of "sociability as cooperation" (39 f.) or a small subchapter on 'targeted advertising' on Facebook (p. 168), consisting of only two loosely joined citations from Facebook's privacy policy. Given that advertising is so crucial to Fuchs's argument about value creation and user exploitation, a reader would clearly expect some elaboration on how a privacy policy for users relates to the 'commodification of data' (p. 168). In chapter two, we read summaries of concepts that have yet to be introduced, e.g. p. 49 on participation and power (Chapters Three and Four) or the "philosophical groundings of the Internet", although Fuchs here only enumerates critical (and less critical) concepts of Web 2.0 (33-37). In terms of style, Fuchs's comradely approach to his assumedly younger readers is at times ill-fitting and often at odds with the theoretically denser passages, e.g. where a term like "heteronomous societies" would certainly merit some explanation (p. 43). When Fuchs makes the case for reading Marx as a theorist of the 
Internet avant la lettre, he leaps quickly from Marx's possibly more modest "anticipation of the concept of the Internet" (p.12, emphasis added) to the catchy slogan that "Karl Marx invented the Internet!" (p.13). While some of the editorial faults should be easy to remedy in subsequent editions, the more discursive and argumentative leaps also reveal Fuchs's style and way of thinking. The overall Marxist framework remains solidly anchored to questions of domination, power, ownership and exploitation, and any contravening or more nuanced arguments are either tweaked and accommodated or simply left out.

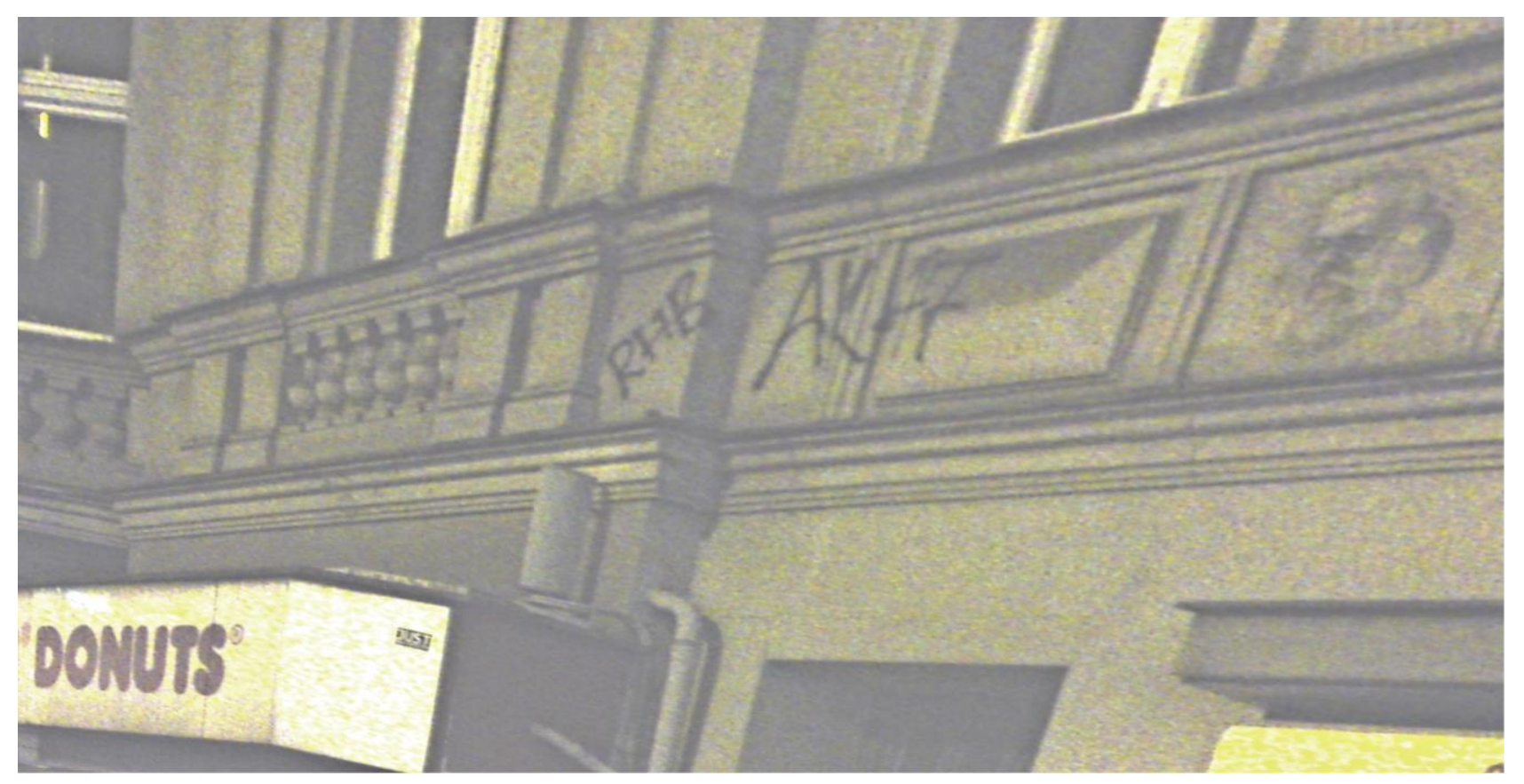

\section{II) Four Issues with Fuchs's Perspective of Social Media}

\section{Issue 1) Introduction, Theory or Critique?}

There is an unresolved ambivalence in Social Media as to whether it is an introduction, a theory or a critique. The book starts with some well-known examples of social media being associated with social change in society - social media and the Arab Spring, social media and the Occupy movement, unpaid work at the Huffington Post - before more theoretical questions and concepts are introduced. Instead of an introduction to social media, it becomes clear that Fuchs wants to develop a "critical theory" (2014a: 11) of social media, a promise that is never quite fulfilled but that seems to have been the original intention. From this perspective, the introduction then appears more like an initiation to critical theory, which Fuchs defines in the following way: "Critical theory holds not only that theory is always political, but also that critical theory should develop analyses of society that struggle against interests and ideas that justify domination and exploitation" (2014a: 17, emphasis added). Invoking the long tradition of Marxist critical theory, Fuchs deliberately sidetracks the task of introducing the study of social media and makes the case that theory must formulate political objectives, must expose forms of domination and, as a consequence, can only be 
critical if it is Marxist! The above definition, in light of Fuchs's more recent writings on social media, has the troubling consequence that other theories, which do not 'struggle against interests' can easily appear as not being critical. This rhetorical shift, inherent in Fuchs's conception of critical theory, but taken to new extremes, risks marginalising the relevance of research that is not devoted to a political struggle. On this point, Loeb has asked "how effective is a critical introduction if its conclusion offers a heads-and-tails choice between "barbarity of capitalism or ... socialism"?" (2014).

But Fuchs also risks ridiculing the political aims of critical theory when he brings down major theoretical concepts like ideology to comparatively banal examples. Fuchs discusses ideology as the "practices and modes of thought that present aspects of human existence that are historical and changeable as eternal and unchangeable" (2014a: 17). Ideology masks power relations, rationalises world views and aims to present social (political, cultural) conditions as unchangeable, ordered by eternal principles or founded on historical continuities. Ideology is an important concept when discussing social media from a critical theory perspective. We may think of an ideology of participation driving concepts of sociality. Or we can assess the ideology of collaboration in relation to labour and the shifting of entrepreneurial risk to free-lancers. We may even question social media through the historicity of the 'Californian Ideology', where New Age spirituality joined sociotechnological utopianism to lay the philosophical and practical association of digital, networked media with societal improvement and economic profit (Barbrook \& Cameron 1996; Turner 2006; Barbrook 2007). But Fuchs argues that ideology is at work when users cannot imagine moving a list of contacts from a dominant platform like Facebook to another platform, because Facebook has created the unquestionable standard in Social Media and presents itself as an unchanging entity! This seems far below the capacity of Fuchs to explain a concept like ideology. But it also feels like Fuchs overstates the significance of what he has to say about social media in place of what he wants to say about the significance of critical theory. According to Stephensen, who wrote an excellent critical essay on Fuchs's recent Culture and Economy in the Age of Social Media (2015b), Fuchs's aim is not to offer a theory of social media in the present, but to "revive Marxism vis-à-vis communication studies in the digital age" (Stephensen 2015: 155). The order of words here is important. Through the given relevance of, and interest in, social media among the public and scholars alike, Fuchs brings back Marxist critique in an archaic form to underline its relevance in the present. In a recent response to Nicolas Garnham, founder and former director of CAMRI, Fuchs explicitly states that "the political economy of the media and the Internet requires Marxian theory" (Fuchs 2015c: 10, emphasis added). From such a perspective, any non-Marxian analysis of the media, the Internet or social media is neither critical nor investigative but can be easily relegated to a discursive position of complicity with the exploitative, capitalist system.

One consequence of clinging to the classics of Karl Marx verbatim in relation to social media is that the specific historical context of Marx's theorising becomes a pattern of social relations projected on a scale of 1:1 to the present. Through this schema, Fuchs overlooks distinctive characteristics of present social media economies, cultures and their wider environment that have changed since the early phase of capitalism. This theoretical inadequacy becomes very apparent when we take the 
example of data. Neither in Social Media nor in Culture and Economy do we find any working definition of what Fuchs means by data. Fuchs assigns central importance to data in his writings on social media because data is the basis of value creation and exploitation in the digital economy. But rather than explaining in what ways data is produced, processed, owned and used (and by whom!), he makes an ideology of data as the new coal. Fuchs reifies data as an obscure entity of mythical dimensions without explaining it. The data he discusses in detail is often modelled on the kinds of data that individual platforms like Google (search) or Facebook (social metrics) themselves use in their business models. For a theory of social media, however, differentiating what kinds of data are needed for functional and communicational purposes, and how and what data is exploited, seems crucial and unavoidable. Admittedly, different kinds of data also allow for new forms of productivity, collaboration and cooperation to emerge that involve social media, open data or open source software.

On a technical level, the precondition of digital communication across platforms and devices is that data is structured in uniform ways to be meaningful for computers, e.g. through the adoption of the HTML standard for websites (Berners Lee \& Fischetti 2000). Standards for data are a requirement to achieve what is commonly called interoperability, the standardisation of different systems, platforms and hardware to communicate and work together. On the economic level, the development of standards in data structures and processing is what drives a broad range of new applications. Developing open application programming interfaces (APIs) for social media platforms, for example, has contributed to the variety of services that are common today, while also creating totally unforeseen use scenarios for social media, e.g. disaster management through social media analysis. Each plugin, each app, each tiny script that joins bodies of data or simplifies menial (and not so menial) tasks contributes to the value created by users on social media and on the web in general. Admittedly, the more data is connected and the more applications feed off each other, the more data can be collected and analysed.

But user data is also becoming "ordinary" itself (Kennedy 2016). Using open-source data and tools, apart from actively determining how private data is generated and processed (through privacy or browser settings), is nowadays less of an expert science than it used to be. The ongoing lawsuit by Austrian student Max Schrems against Facebook's privacy policy on the European level is equally a sign that power asymmetries between transnational dot-com corporations, legislators and users are also subject to change. Instead of blackboxing data as an ominous entity, scholars of social media (whether as an economy, a culture or communications space) need to be able to distinguish functional machine-to-machine data $(\mathrm{M} 2 \mathrm{M})$ from user metrics, content and statistical or security data. Whether the analysis of so called 'data points', to use Carolin Gerlitz's term, is useful and relevant for a research question, needs to be determined on a case to case basis. The wide variety of methodological approaches for analysing Twitter data, for example, is an indication that the significance of data in social processes is not likely to be explained by a single theoretical framework (see also Beer 2013). As recent debates in the humanities and social sciences show (Andrejevic, Hearn \& Kennedy 2015; boyd \& Crawford 2013; Gitelman 2013), the epistemological status of data or big data, its usability in research or its unquestioned relevance as a means to 
knowledge is hardly going uncontested. In relation to social media, scholars and programmers are beginning to reconstruct volatile and fluid processes of communication through independently developed scraping, mining and analysis tools for web data while also critically questioning both the role of data in communication and the abilities (and impossibilities) of digital methods to uncover them (Rogers 2013; Rieder \& Gerlitz 2013; Weller et al. 2014). The kind of reified black box that Fuchs invents for data appears rather grey, and is more likely a network of relations than a box, a highly differentiated political, technical and social field of knowledge, power and activism that is equally worthy of critical attention and theorisation. To understand the motivations, relations and dependencies in this field, Fuchs has little to offer in theoretical terms because he prefers to foreground questions of ownership, domination and exploitation.

\section{Issue 2) Social Media or Social Media®?}

Fuchs bases his political claims for a reinvention and re-imagination of social media on the argument that the beneficial uses of digital media need to be disentangled from their capitalist form of organisation. The distinction between cognition, communication and collaboration as general social processes (2014a: 42-49), and the standardisation and commercialisation of such processes in social media platforms, prepares the ground for his critique of social media as they are today. This opposition is reminiscent of Raymond Williams's older distinction between communication as a general human activity and the development of communications as commercial enterprises (1976: 1). Williams argued that the "practical use of communication is the sharing of real experience." What advertising and publicity do, in contrast, is promote a "perversion" of a fundamental human need through the "packaging of experience" in glossy images and commercialized media formats (Williams 1971: 25). Fuchs himself has been reviving Williams as a cultural materialist in Culture and Economy (2015b). But in contrast to Williams, one of the founding fathers of cultural studies, Fuchs sharply opposes rather than relates the social and the branded social media, or communication and communications in Williams's terminology. Fuchs thus creates antagonistic formations between the positive social media and the capitalistic social media ${ }^{\circledR}$ for the sake of theoretical radicalism. Throughout his recent writings he identifies social media ${ }^{\circledR}$ only with particular brand names like Google or Facebook, given that these companies are undoubtedly powerful market players in the digital economy. Singling out the big players has the advantage, at least for Fuchs, that they can be identified with primary products. But more importantly, through the choice of well-known platforms, Fuchs can address his criticism of particular troubling aspects which concern the social media economy as a whole (lack of transparency, privacy, targeted advertising) to specific actors. This fixation on particular 'applications' like Google, Facebook or Twitter, however, creates the impression that particular companies define practices of exploiting user data that remain opaque to users and that need to be revealed to the latter through Fuchs's writings.

The discussion of Google as a "good or evil search engine" (title chapter 6, Social Media) connects reflections on its ubiquity as a search engine, its ownership structure, its surveillance of user 
behaviour and its violation of EU data protection with Fuchs's own study of how Google employees are exploited through playlabour. The chapter ends on the conclusion that Google is both "God and Satan" (title Ch. 6.5) and that "Another Google is possible" (2014a: 150). Alas! Apart from his own study of what Google workers reveal publicly about their working conditions, the chapter on Google offers little more than commonplaces, tried and established knowledge that is as ubiquitous as the reference to the Page Rank algorithm. Furthermore, it is not made plausible why Google in particular stands for exploitative practices or why it is primarily a social media company.

In regard to Twitter, Fuchs presents his own study of top trends from 2009 to 2012, which reveals that entertainment subjects outnumber political subjects by far. This leads him to conclude that "Twitter is predominantly an information medium, not a communication tool. It is predominantly about entertainment, not about politics" (199). Although \#JustinBieber or \#iranelection are probably not referenced by the same networks of social actors, Fuchs argues that Twitter is inherently geared towards entertainment rather than politics, because the absolute numbers of trends and tags for a given year suggest that. If we compare Fuchs's earlier findings with the more recent annual report by Twitter from 2015, and focus only on the 'news' category, the picture looks quite different:

\section{1. \#jobs; 2. \#Quran; 3. \#ISIS; 4. \#PrayForParis; 5. \#LoveWins; 6. \#CharlieHebdo; 7. \#JeSuisCharlie; 8. \#BlackLivesMatter}

[Source: https://2015.twitter.com/top-trends, retrieved 14 Dec. 2015]

Whether Twitter is used for entertainment or political action or simply as a form of personal communication depends in large part on the interests and practices of its users. These shift from year to year, from day to day. Just because Justin Bieber is the most popular topic in absolute numbers in one year does not systematically exclude the possibility that more controversial, political topics make it to the Twitter agenda, even if the networks are smaller that address them. The issues debated and mentioned on Twitter are not a given of the platform itself. As Segerberg and Bennett have shown in their study of the Occupy Movement, Twitter served as an important aggregator of information and as a resource for thousands of dispersed activist groups (Segerberg \& Bennett 2013). In a review of Social Media, Thomas Swann argues that "[w]hile one needs to be acutely aware of the intended function of corporate social media ... this is not to say that mainstream tools can't be used in the meantime [for political activism]" (Swann 2014: 120). The reason why Fuchs avoids such nuances and prefers to label Twitter as a medium of entertainment is that he is far more interested in debating Habermas's concept of the public sphere from a normative standpoint, only to realise that Twitter may not live up to the expectations the model raises. Why a commercial platform like Twitter should live up to these expectations, or why Twitter should be a public sphere in the normative sense of Habermas, however, is not problematised by Fuchs. His method is rather to mirror popular conceptions of social media - both in scholarship and the public debate - in order to make provocative theoretical arguments.

The trouble with this method is that he has to balance his rejection of corporate structures with the positive social aspects of certain applications without giving up the fundamental antagonism of 
social versus social media®. This oddity becomes apparent, when he discusses Wikipedia as "an anticipation of the communist mode of production" (2014a: 247), as a model of non-corporate, collaborative production and of participatory democracy. At the same time, Fuchs has to admit that "Wikipedia work is stratified today" (ibid.), that there are power hierarchies between the "welleducated elite" - those who have resources to contribute disproportionately more - and those who never or rarely edit an article or take part in a discussion (see also Loeb 2014). This point is restated by a range of scholars (Sunstein 2006; Sanger 2009), and confirmed in Wikipedia's own public statistics on editor activity: Among the 10,000 most active editors (excluding bots), the number of edits already declines dramatically from well over one million for each of the first top four to less than 7,000 among the last four. ${ }^{1}$ Despite these figures and widely acknowledged discrepancy between ideal and reality, Fuchs clings to Wikipedia as a model for social media (without the trademark). More controversially, however, he likens Wikipedia to "communist cells [that] need to be developed, extended and intensified in order to create a communist Internet and a communist society" (2014a: 243). The exaggeration here is deliberate and intentional, but is achieved only on the back of an antagonism pitched to extremes. Apart from Facebook and Wikipedia, it is astounding that Fuchs makes no acknowledgement for the myriad projects, networks and initiatives (e.g. the Electronic Frontier Foundation, the Mozilla community, the open source software platform Github) that are all putting digital collaboration into practice, voicing demands for digital rights and open data, creating open software, and freely sharing resources to improve society. And many of them are actually using Twitter, Facebook and Google as well. The perceived incompatibility of corporatized and grassroots social media is a theoretical chimera that Fuchs needs to rhetorically back up his political agenda.

\section{Issue 3) Exploitation and Free Labour}

The issue of exploitation and free labour in relation to social media and the digital economy in general has, over the last years, been the most controversial among scholars (see for example the discussion in Banks \& Deuze 2009; Beer 2013: 101-112). The role of user data in the digital economy can certainly not be underestimated. The broad interdisciplinary interest in this subject confirms that scholars today are less prone to utopian fallacies when it comes to assessing the social impact of new

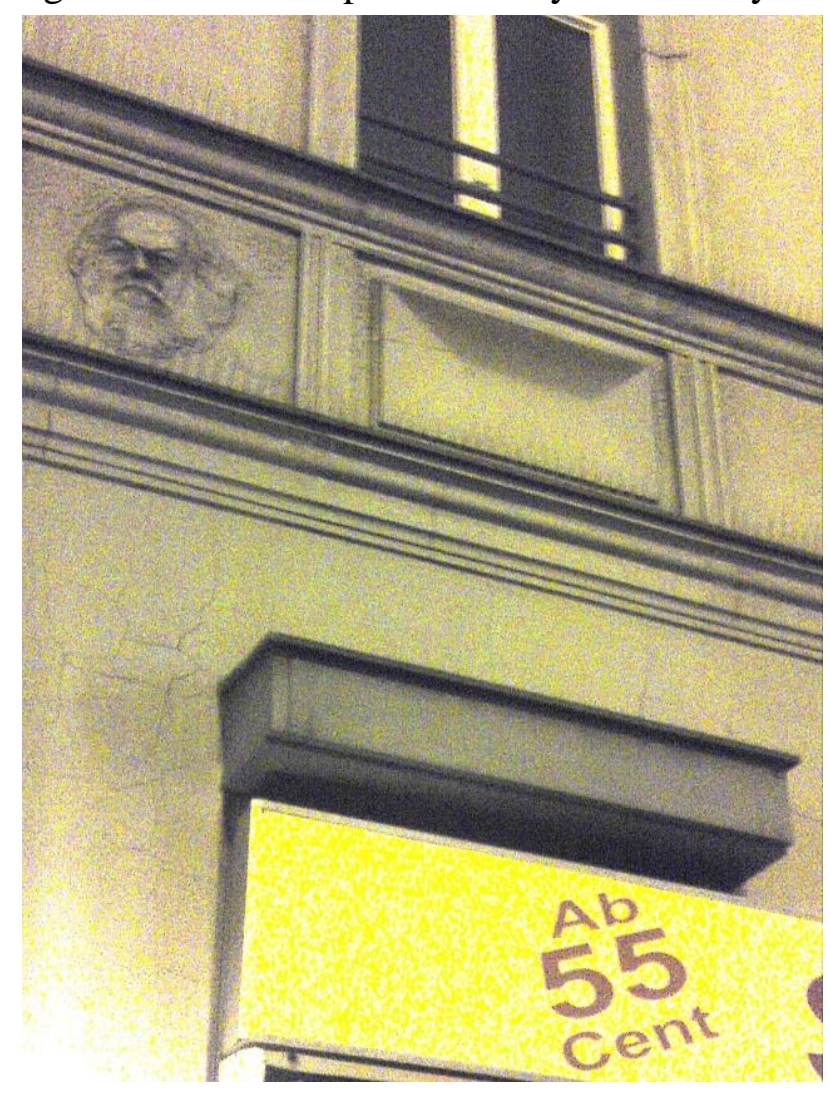
technologies.

\footnotetext{
${ }^{1}$ See https://en.wikipedia.org/wiki/Wikipedia:List_of_Wikipedians_by_number_of_edits) accessed February 9, 2016.
} 
When Fuchs emphasises that users are exploited as productive forces through their gratuitous contributions to social media platforms, he typically justifies this strong term by pointing to the international division of digital labour (IDDL) framework. In numerous publications (2013; 2014a: 117f.; 2014c; 2015b) he draws up the direct connection from exploitative working conditions in African mines, Chinese electronics sweatshops, Indian software and service industries to the equally exploitative headquarters of Google, Facebook and others in California. For him, the miners and hardware assemblers are as exploited as the software engineers at Google who are forced into playlabour. Invoking the analogy of African cobalt mines to Manchester's 19th century coal mines, Fuchs justifies the relevance of a Marxist analytic framework in relation to social media in no small measure by insisting on the exploitation of users by an egoistic class of capitalists (purportedly all living in California): "Silicon Valley is shaped by a geography of inequality, death, stress and the destruction of human livelihood. This is the foundation of the capitalist ICT industry and its profits" (Fuchs 2013: 19). In his discussion of Google's ownership structure (2014a: 128-131), the fact that the two founders own disproportionately more shares than any other leads Fuchs to argue that "the people using Google or working for Google are permanently exploited and dispossessed of the profit that they create" (2014a: 130, emphases added). Users are exploited because through their behaviour, search and preferences they provide data that is aggregated and sold to advertisers; workers are exploited because they have to use their lean off-hours to foster social causes or maintain Google's creative community. Lilly Irani and others have also pointed to the importance of less prominent service workers who are sifting through heaps of data, identifying patterns and cleaning up search results, so called "data janitors". Irani writes: "Google's abundantly productive, nonhierarchical and playful workplace seemed to rely on hidden layers of human data work: subcontractors who were off the books, out of sight, and safely away" (Irani 2015).

Although Fuchs suggests that all forms of labour associated with the global electronics, service and software industries rely on forms of exploitation, he does not equate forms of existential or coerced labour with the seemingly pleasurable, unremunerated forms of labour that users of social networks engage in. He points out that exploitation of labour takes different forms because "capital seeks opportunities to reduce labour costs in order to maximise profits. It takes every opportunity to create colonies of ongoing primitive accumulation that are based on low-paid, unpaid or precarious labour" (2015c: 5). Fuchs conceives of users of social media primarily through the lens of the 'audience commodity' (2012b), the creation of targetable audience segments for advertising clients through user metrics. But he also acknowledges that "not all usage of social and digital media is labour, that is, a generation of economic value" (2015c: 8). As a consequence, Fuchs seems to agree that social media usage may not be exploitation per se, since users can profit from content, relations and resources in immaterial ways as well. A similar argument is put forward by Paul Rey, who discusses exploitation in relation to social media. Rey foregrounds that sharing content in social media is a form of "consum[ing] others' consumption" (2012: 412), of observing, interacting with and distributing one's own perception of the social through the networked medium. The benefits of sharing "immaterial information" within a wide network of actors create "a distinct type of value", which differs in kind for the users and the owners of such sites (Rey 413). Thus, even within a Marxist framework of analysis, exploitation can be differentiated. Rey concludes that "the rate of 
exploitation on social media is inversely related to the utility of the content to the prosumer" (415).

It was Mark Andrejevic who pointed out the difference between user-generated content and usergenerated data (2009: 418). Users may create content on a voluntary and gratuitous basis, and the sheer amount of content thus created draws new users to a platform, thereby increasing the value of the platform for each new user exponentially. But this content is interesting to owners only insofar as it makes it possible to gather data about users' social behaviour. As James Reveley has argued in a crushing critique of Fuchs's and Rey's political economy of social media, "it is user data (UGD) and not users themselves, which is the most valuable informational commodity social media firms sell to advertisers" (2013: 521). A single tweet, to take just one example, has only 140 characters on the content side, yet is defined by a host of metadata tags that each track particular properties of the message and its journey through the network. This metadata remains largely obscure to users and is the source for statistical and algorithmic aggregation. Defining and implementing how such data can be made useful commercially, however, requires actual investments, actual expertise and resources. That "ads ... are targeted to individual tastes and preferences" (Fuchs 2015c: 2) is the result of research, investments and development by social media companies, not a direct result of user activity. When Fuchs argues that the "audience commodity has in the case of Google and Facebook been dialectically transformed into a user-generated data commodity" (ibid.), he seems to imply that the sheer activity of users generates the data commodity, not the efforts of the companies and their employees.

Whether users and employees of social media are equally exploited hinges on the contentious issue of the degree to which free labor is factored into the calculation of surplus value. Despite his more recent acknowledgement that not all forms of labour create economic value, Fuchs has consistently argued that the sheer amount of gratuitously created content by users is an infinite resource for the creation of surplus value on the side of platform owners (2010). In a widely quoted article on free labour and the early web, Tiziana Terranova has pointed out that the creation of content and the development of online communities took place on a voluntary and 'free' basis on the early web. This unremunerated, cultural work contributed to the attractiveness of the new online communication environment for newcomers: "Within the early virtual communities, we are told, labor was really free: the labor of building a community was not compensated by great financial rewards (it was therefore "free," unpaid), but it was also willingly conceded in exchange for the pleasures of communication and exchange (it was therefore "free," pleasurable, not imposed)." (Terranova 2003, n.p.).

In a similar vein, David Hesmondhalgh has argued that individual and collective rewards from participating in social media and the creation of content can take many - symbolic, immaterial, social - forms. That cultural or social work is often not rewarded in pecuniary terms should not imply that it is not rewarded at all: "it seems dangerous to think of wages as the only meaningful form of reward" (Hesmondhalgh 2010: 278). Instead of assuming an exploitative relation all along and for any kind of activity, Hesmondhalgh proposes to speak of "degrees of exploitation" to be able to differentiate forms of exploitation in an intersectional perspective on social inequality 
(Hesmondhalgh 2015). Failing to acknowledge how class, gender, education, income and other factors influence degrees of exploitation, both in terms of usage and in terms of salaried work, for social media platforms or the creative industries risks overdetermining the rate of surplus value as the only indicator of exploitation. James Reveley argues that "Fuchs and Rey direct Marxist social media analysis into a conceptual cul-de-sac" (Reveley 2013: 531) because they imply that the endless availability of users and their gratuitous content creation creates equally endless surplus value and thus exploitation.

To put this argument in even harsher terms, Nicholas Garnham has attacked Fuchs for conflating dimensions of social inequality in favour of theoretical radicalism: "Fuchs here exemplifies a common failing of the return to Marxism literature - its essentially religious cast, operating through the ritual incantation of texts rather than through argument and evidence. Thus, the levels of exploitation Fuchs finds are already inscribed within the theoretical definitions rather than found within the real world, and this results in a very one-dimensional view of exploitation, and thus of class" (Garnham 2015: 2). Exploitation is certainly a useful concept for analysing power relations, dependencies and hegemonic structures in the economy of social media. But when it becomes shorthand to conflate very different social relations, types of value creation and forms of interaction, it loses its analytic focus. Further debate on this subject will very likely need to consider how user-generated content and interaction relate to the creation and exploitation of user-generated data for commercial and public purposes. Instead of regarding the value of such data only in commercial terms, further research will need to address in what contexts and in what ways user data can be accessed, analysed and understood as part of social processes. Renée Ridgway, in a recent article on 'personalisation as currency' in the digital economy, has summarised this concern quite aptly: "Trading in privacy for personalisation and convenience has become the default modus operandi as the tools we use every day, from smartphones to search engines and websites, capture our personal data. (...) The question of what our data is actually worth to us remains open" (Ridgway 2015). The simple dichotomies in Fuchs's globalising view of exploitation (along with his rhetoric of class struggle) obfuscate rather than explain the new modalities, dependencies and power relations between operators and users of social media platforms.

\section{Issue 4) The versatility of user practice}

As a last point of criticism of Fuchs's view of social media, it is pertinent to bring back the question of the role and significance of users to the debate. It is quite surprising that Fuchs speaks of users in a highly abstract and theoretical sense, given that the value and popularity of social media are based on user activity. Instead of conceding (or even acknowledging) that the variety of contexts in which social media play a role may be incompatible with a single analytic framework, Fuchs focuses on the audience commodity and data as the only commodities that matter in relation to surplus value. He decidedly excludes any reference to specific use cases or user motivations, probably with the exception of social media in times of revolutionary upheaval as in the Arab Spring or the creation of common knowledge in Wikipedia. But even a cursory list of potential uses and motivations shows 
that Fuchs can achieve theoretical closure only at the price of treating users as an abstract collective entity. Think of a single mother (or father) looking for advice and companionship on child rearing. Think of a political activist against narco violence in Mexico looking for allies and support. Think of a specialised factory of industrial gear looking for clients overseas. Or take the (trite) example of a teenager looking to connect and stay in touch with peers. The very heterogeneity of social contexts - ranging from advice on quotidian affairs to political action, from business development to maintaining social relations - is not per se a disqualification of analytic frameworks that foreground exploitation. But, by assuming that social, cultural or political processes that involve social media can be reduced to, and are in fact explained by, the exploitative dimension of commercialising user data, Fuchs fetishises data without explaining its contextual relevance. He has problems accepting that social media, just like the Internet in general, "[do] not inherently promote freedom or oppression, hierarchy or decentralization, privacy or social control, individualist or collectivist values, markets or socialism. Considered narrowly as a technology, it [the Internet] is capable of participating in any combination of social orders" (Agre 2002: 184). Through Fuchs's lens, it is difficult to account for the variety of forms and constellations in which social media are embedded as everyday routines and practices apart from the audience commodity. Fuchs argues that the full range of data mining is not apparent to users, but he somehow also assumes that users need to understand the political economy of social media to overcome their own ignorance. The overt focus on users as audiences and commodities is also in stark contrast to the growing body of research that questions the very uniformity of audiencehood (and its alleged passivity) - ranging from classics in reader-response theory (e.g. Iser 1978, Fish 1980; Radway 1984; 1988) to the contributions of ethnography, cultural studies and audience and reception studies to understand and account for the plurality of meanings and practices generated in the interpretation and appropriation of symbolic content (e.g. the work of Elizabeth Bird (2011; 2010; Couldry 2012; Morley 2007; Moores 2005), to more comparative and critical studies of Western and non-Western concepts of publics and audiences (e.g. Butsch \& Livingstone 2014). To sum up, Fuchs's overly theoretical account of social media users has little to say about user practices or levels of agency. Although the domination, ownership, exploitation and power are important categories in the analysis of social media's wider political and cultural economy, Fuchs's theoretical grounding overshadows or even makes it impossible to differentiate these categories in varying contexts of social media usage.

\section{Not yet a conclusion}

I wrote in the beginning that Fuchs's short introduction to social media enjoys a relatively unique market position and is likely to be used in a variety of teaching contexts. It's brief; it's wellstructured and supplemented with helpful questions and resources for further study. The book also stands out as a critical introduction, in distinction from the gamut of introductory literature on social media marketing, digital media or online media. In its critical and political ambitions, however, the view of social media that Fuchs promotes risks being locked into a position of theoretically-motivated radicalism. Through his perspective of the political economy of social media, the object he puts into focus appears starkly unfamiliar, which is not per se a point of 
criticism. Stripped of its alluring surfaces, its seamless interfaces and promises of community, Fuchs hopes to expose the ideological complicity of social media with exploitation in the context of a globalised Capitalist economy and culture. His Marxist framework foregrounds questions of ownership, power and domination over considerations of user practice or agency. This basic antagonism of core Marxist versus culturalist views of media in society is also a recurrent struggle in scholarship. Already in 1958, Raymond Williams thought it was an "unanswerable question" whether the economic element in any analysis of culture could be determining or not. His main point was that "the difficulty lies in estimating the final importance of a factor which never, in practice, appears in isolation" (Williams 1963: 272). Now Fuchs certainly wants to embed social media in their wider cultural and political environment, but the terms of his analysis derive in principle from a consideration of ownership and power, and in consequence foreground exploitation - of minerals, of workers, of users. But whose media is it? Ownership in the legal sense of the word does not suffice to critically evaluate what kind of meaning, what importance social media may have in everyday life or for a self-affirmed "digital underclass". And value can have a range of meanings, one of which is economic profit. The issues that Fuchs raises in relation to social media and the Internet in general are important, and to a degree are often overlooked in current debates. But they are not as overlooked and marginal as he would like to have them, if you regard the important contributions made by e.g. van Dijck (2013), Gillespie (2014), Lanier (2010; 2014), Lessig $(1999 ; 2004)$ or Zittrain (2008). The most controversial point about Fuchs's view of social media remains his conjunction of their capitalist form of organisation as an explanation of the corruption of human ends and needs, which in turn serves as a reason to demand a socialist (read: commonist or communist) society. In a remarkable passage worth quoting at length, Raymond Williams criticised this socialist utopianism on the basis that it was an effect of theoretical positions taken in advance of analysis. Just replace 'bourgeois' with 'capitalist', and Williams could be commenting on Fuchs:

If you get into the habit of thinking that a bourgeois society produces, in a simple and direct way, a bourgeois culture, then you are likely to think that a socialist society will produce, also simply and directly, a socialist culture, and you may think it incumbent on you to say what it will be like. As a matter of fact, most of the speculation about the 'socialist culture' of the future has been no more than a Utopian habit; one cannot take it very seriously (Williams 1963: 273).

That Fuchs is serious about his critical project is beyond doubt. But to have a wider impact on theorising social media outside his circle of followers will mean to engage more thoroughly with the different strands of research on social media, as well with facets of media practice and the meaningfulness of media practices for users, even if it is from the perspective of critical theory. Whether he is content preaching to the choir or whether he can listen to the tunes of a wider community remains to be seen. 


\section{Acknowledgements}

I thank Henrik Bødker, Helen Kennedy and Boris Vormann for their suggestions on an earlier version of this review essay.

Photos: All photos taken by author on Karl-Marx-Strasse 1 in Berlin, where the vignette of the great thinker looks down on thrift shops and a Dunkin' Donuts outlet. Licensed Creative Commons $C C B Y$. Thanks to Tomasz Stompor for pointing out this architectural gem.

\section{References}

Agre, Philip E. (2002). "Cyberspace as American Culture." Science as Culture 11(2): 171 189. doi:10.1080/09505430220137234

Andrejevic, Mark; Hearn, Alison; Kennedy, Helen. (2015). "Cultural Studies of Data Mining: Introduction." European Journal of Cultural Studies 18(4-5): 379-394. doi:10.1177/1367549415577395.

Andrejevic, Mark. (2009). "Exploiting YouTube: Contradictions of User-Generated Labor." The YouTube Reader, edited by Pelle Snickars; Patrick Vonderau, 406-423.

Stockholm: National Library of Sweden.

Banks, John; Deuze, Mark (2009). "Co-Creative Labour." International Journal of Cultural Studies 12(5): 419-431. https://dx.doi.org/10.1177/1367877909337862

Barbrook, Richard (2007). Imaginary Futures. From Thinking Machines to the Global Village. London; Ann Arbor: Pluto Press

Barbrook, Richard; Cameron, Andy. (1996). "The Californian Ideology".

http://www.hrc.wmin.ac.uk/theory-californianideology-main.html. Retrieved February 18, 2016.

Beer, David (2013). Popular Culture and New Media: The Politics of Circulation. Basingstoke: Palgrave Macmillan.

Berners-Lee, Tim; Fischetti, Mark (2000). Weaving the Web. The Original Design and Ultimate Destiny of the World Wide Web by Its Inventor. San Francisco: HarperBusiness.

Bird, Elizabeth. (2011). "Seeking the Audience for News. Response, News Talk, and Everyday Practices." The Handbook of Media Audiences, edited by Virginia Nightingale, 489-508. Oxford: Blackwell.

Bird, Elizabeth. (2010). "From Fan Practice to Mediated Moments: The Value of Practice Theory in the Understanding of Media Audiences." Theorising Media and Practice, edited by Birgit Bräuchler; John Postill, 85-104. New York: Berghahn.

Bruns, Axel (2008). Blogs, Wikipedia, Second Life, and Beyond. New York: Peter Lang. Butsch, Richard; Livingstone, Sonia (eds.) (2014). Meanings of Audiences: Comparative Discourses. London: Routldege.

Couldry, Nick (2012). Media, Society, World: Social Theory and Digital Media Practice. Cambridge: Polity. 
Davis, Jenny. (2014). "\#review: Social Media: A Critical Introduction." The Society Pages. March 20, 2014. https://thesocietypages.org/cyborgology/2014/03/20/review-socialmedia-a-critical-introduction/ [accessed February 9, 2016].

Fish, Stanley (1980). Is There a Text in This Class? The Authority of Interpretive Communities. Cambridge MA.: Harvard University Press.

Fuchs, Christian (2015a). Reading Marx in the Information Age: A Media and

Communication Studies Perspective on Capital Volume I. Abingdon: Routledge.

---. (2015b). Culture and Economy in the Age of Social Media. Abingdon: Routledge.

--. (2015c). "Against Theoretical Thatcherism: A Reply to Nicholas Garnham." Media,

Culture \& Society. doi:10.1177/0163443715612542.

---. (2014a). Social Media. A Critical Introduction. Los Angeles: Sage.

---. (2014b). Occupymedia! The Occupy Movement and Social Media in Crisis Capitalism.

Alresford: Zero Books.

---. (2014c). Digital Labour and Karl Marx. Abingdon: Routledge.

---. (2013). "Theorising and Analysing Digital Labour: From Global Value Chains to Modes of Production." The Political Economy of Communication 2(1): 3-27.

---. (2012a). Foundations of Critical Media and Information Studies. Abingdon: Routledge.

---. (2012b). "Dallas Smythe Today - the Audience Commodity, the Digital Labour Debate,

Marxist Political Economy and Critical Theory. Prolegomena to a Digital Labour

Theory of Value." tripleC 10(2): 692-740. www.triple-

c.at/index.php/tripleC/article/download/443/414

---. (2010). "Labor in Informational Capitalism and on the Internet." The Information Society 26(3): 179-196. doi:10.1080/01972241003712215.

---. (2008). Internet and Society. Social Theory in the Information Age. Abingdon:

Routledge.

Fuchs, Christian; Sandoval, Marisol (eds.) (2014). Critique, Social Media and the Information Society. Abingdon: Routledge.

Garnham, Nicholas (2015). "Book Review: Digital Labour and Karl Marx." Media, Culture \& Society. doi:10.1177/0163443715612543. Published online 3 Dec. 2015.

Gillespie, Tarleton. (2014). "The Relevance of Algorithms." Media Technologies. Essays on Communication, Materiality, and Society, edited by Tarleton Gillespie; Pablo

Boczkowski; Kirsten Foot, 167-194. Cambridge MA.: MIT Press.

Hesmondhalgh, David. (2015). "Exploitation and Media Labor." The Routledge Companion to Labor and Media, edited by Richard Maxwell, 30-39. Abingdon: Routledge.

---. (2010). "User-Generated Content, Free Labour and the Cultural Industries." Ephemera.

Theory and Politics in Organization 10(3/4): 267-284.

Irani, Lilly (2015). “Justice for 'Data Janitors." Public Culture 15 January 2015.

http://www.publicbooks.org/nonfiction/justice-for-data-janitors.

Iser, Wolfgang (1978). The Act of Reading. A Theory of Aesthetic Response. London:

Routledge \& Kegan Paul.

Kennedy, Helen (2016). Post, Mine, Repeat. Social Media Data Mining Becomes Ordinary.

Basingstoke: Palgrave Macmillan. 
Lanier, Jaron (2014). Who Owns the Future? New York: Simon \& Schuster.

---. (2010). You Are not a Gadget. A Manifesto. New York: Knopf.

Lessig, Lawrence (2004). Free Culture. The Nature and Future of Creativity. New York:

Penguin.

--- (1999). Code and Other Laws of Cyberspace. New York: Basic Books.

Loeb, Zachary. (2014). "All Hitherto Existing Social Media." boundary 2 - An International Journal of Literature and Culture. September 23, 2014.

http://boundary2.org/2014/09/23/all-hitherto-existing-social-media/ [accessed

February 9, 2016].

Moores, Shaun (2005). Media/theory: Thinking About Media and Communications.

Abingdon: Routledge.

Morley, David (2007). Media, Modernity and Technology. The Geography of the New.

London: Routledge.

Panofsky, Erwin ([1927] 1997). Perspective as Symbolic Form. Translated by Christopher

S. Wood. New York: Zone Books.

Papacharissi, Zizi (2015) "Toward New Journalism(s)— Affective news, hybridity, and liminal spaces.” Journalism Studies, 16 (1): 27-40.

Radway, Janice (1984). Reading the Romance: Women, Patriarchy, and Popular

Literature. Chapel Hill: University of North Carolina Press.

---. (1988). "Reception Study: Ethnography and the Problems of Dispersed Audiences and

Nomadic Subjects." Cultural Studies 2(3): 359-376.

doi:10.1080/09502388800490231.

Reveley, James (2013). "The Exploitative Web: Misuses of Marx in Critical Social Media

Studies." Science \& Society 77(4): 512-535. doi:10.1521/siso.2013.77.4.512.

Rey, Paul. J. (2012). "Alienation, Exploitation, and Social Media." American Behavioral Scientist 56(4): 399-420. doi:10.1177/0002764211429367.

Ridgway, Renée (2015). "Personalization as Currency." APRJA - A Peer-Reviewed Journal About Datafied Research 4(1). http://www.aprja.net/?p=2531.

Rieder, Bernhard; Gerlitz, Carolin (2013). "Mining One Percent of Twitter: Collections,

Baselines, Sampling." M/C Journal 16(2). http://journal.media-

culture.org.au/index.php/mcjournal/article/viewArticle/620. Retrieved February 18,

2016.

Rogers, Richard (2013). Digital Methods. Cambridge MA.: MIT Press.

Sanger, Lawrence M. (2009). "The Fate of Expertise After Wikipedia." Episteme 6(1): 52-

73. doi:10.3366/E1742360008000543.

Segerberg, Alexandra; Bennett, W. Lance (2013). The Logic of Connective Action. Digital

Media and the Personalization of Contentious Politics. New York: Cambridge

University Press.

Smythe, Dallas W. (1982). Dependency Road. Communications, Capitalism,

Consciousness, and Canada. Norwood, N.J.: Ablex.

Stephensen, Jan Løhmann (2015). "Towards a Digital Materialism. Review Essay on

Christian Fuchs (2015). Culture and Economy in the Age of Social Media." 
Conjunctions. Transdisciplinary Journal of Cultural Participation 2(2): 154-171. www.conjunctions-ticp.com/article/download/22927/20042

Sunstein, Cass R. (2006). Infotopia. How Many Minds Produce Knowledge. New York: Oxford University Press.

Swann, Thomas (2014). "Review of 'Social Media: A Critical Introduction'." Anarchist Studies, 22(2), 119-120.

Terranova, Tiziana. (2003). Free Labor: Producing Culture for the Digital Economy. Electronic Book Review. Retrieved 21 July 2015 from http://www.electronicbookreview.com/thread/technocapitalism/voluntary.

Thompson, John B. (1995). The Media and Modernity. A Social Theory of the Media. Stanford: Stanford University Press.

Trottier, Daniel.; Fuchs, Christian (eds.) (2014). Social Media, Politics and the State: Protests, Revolutions, Riots, Crime and Policing in the Age of Facebook, Twitter and Youtube. Abingdon: Routledge.

Turner, Fred (2006). From Counterculture to Cyberculture. Stewart Brand, the Whole Earth Network, and the Rise of Digital Utopianism. Chicago: University of Chicago Press.

Weller, Katrin; Bruns, Axel; Burgess, Jean; Mahrt, Merja; Puschmann, Cornelius (eds.) (2014). Twitter and Society. New York: Peter Lang.

Williams, Raymond ([1962] 1976). Communications. 3rd edition. Harmondsworth: Penguin Books.

Williams, Raymond ([1958] 1963). Culture and Society 1780-1950. Reprinted with a postscript. London: Penguin.

Zittrain, Jonathan (2008). The Future of the Internet and How to Stop it. London: Allen Lane.

Christoph Raetzsch is a lecturer at the Division of Journalism Studies of Freie Universität Berlin. He has studied American Literature and Culture, Media Archaeology, Film Studies, and Media Consulting. In his dissertation at the Graduate School of North American Studies Berlin he developed a practice-based approach to study the historical transformation of American news journalism in times of media change. His work has appeared in international journals such as Digital Journalism, Journalism Practice and Media History. His current research is concerned with 'the circulation of communicative objects' (http://futuremaking.space/project/tracing-thecirculation-of-communicative-objects/) and aims to develop and understand digital methods in the study of public online communication. Christoph Raetzsch is a frequent reviewer for various German and international journals and professional associations (ECREA, ICA), and Vice Chair of the Digital Culture and Communication Section of ECREA.

Further links: academia.edu (http://fu-berlin.academia.edu/ChristophRaetzsch) or raetzsch.berlin (http://raetzsch.berlin).

Email: christoph.raetzsch@fu-berlin.de 